\title{
Isolation and identification of Pandoraea spp. From bronchoalveolar lavage of cystic fibrosis patients in Iran
}

\author{
${\text { Mohammad } \text { Tabatabaei }^{1 *} \text {, Mahdi Dastbarsar }}^{1}$ and Mohammad Ashkan Moslehi ${ }^{2}$
}

\begin{abstract}
Background: Pandoraea species are gram negative, motile, non-spore forming, rod shaped and oxidase positive, obligate aerobes bacteria, and have one polar flagellum. Most of Pandoraea species are associated with lung infections in cystic fibrosis patients. Cystic fibrosis is the most prevalent autosomal recessive hereditary disease in the world that affects various organs of the body. The main important cause of death in these patients is lung involvement. This study was conducted to isolate and identify Pandoraea bacterium from bronchoalveolar lavage and sputum samples of cystic fibrosis patients in Shiraz, Iran.

Methods: In this research 31 samples of bronchoalveolar lavage and sputum were examined by culture and PCR method. Then confirmed isolates were evaluated for susceptibility to different antibiotics and ability to produce biofilm.

Results: The results of this study after cultivation, purification and DNA extraction led to the isolation of 4 Pandoraea bacterium by PCR using specific primers. Antibiotic susceptibility test were indicated all isolates were resistant to gentamicin, amikacin and imipenem and susceptible to ciprofloxacin, trimethoprim-sulfumethoxazole, piperacillin and tetracycline. Ability to create biofilm was indicated by some of Pandoraea isolates. According to findings of this study, ability to synthesis biofilm by Pandoraea isolates and resistance to some antibiotics are very important.

Conclusions: Our study notes the role of P. pnomenusa as an emerging pathogen that can cause chronic lung colonization in CF patients. Identification tools need to be accurate and must be based on molecular techniques. Also our findings should raise awareness about antibiotic resistance in cystic fibrosis patients in Iran and ability of including bacterial agents to produce biofilm is an alarm for public health. Thus clinicians should exercise caution about finding of clinical relevance of this pathogen to the infection and prescribing antibiotics, especially in cases of children infections.
\end{abstract}

Keywords: Pandoraea spp., Cystic fibrosis, Bronchoalveolar lavage, PCR, Iran

\section{Introduction}

The genus Pandoraea is composed of aerobic, non-sporeforming, non-nitrate reducing, non-lactose fermenting, and gram negative rods shaped bacteria, with polar flagella. They have been grown at $30-37^{\circ} \mathrm{C}$ in 0.5 and $1.5 \% \mathrm{NaCl}$ or on Drigalski agar, assimilate D-gluconate, L-malate, and phenylacetate, and have catalase, acid and alkaline phosphatase and leucine arylamidase activity [1]. Different species of Pandoraea have been described: P. apista, $P$. norimbergensis, $P$. pnomenusa, $P$. pulmonicola, $P$. sputorum, $P$. fibrosis, $P$. terrae, $P$. oxalativorance, $P$.

\footnotetext{
* Correspondence: mtabatabaei2003@yahoo.co.uk

${ }^{1}$ Faculty of Veterinary Medicine, Shiraz University, Shiraz, Iran

Full list of author information is available at the end of the article
}

faecigallinarum, $P$. vervacti, $P$. thiooxidance and four unnamed genomospecies. The majority of isolates have been isolated from respiratory samples from patients with cystic fibrosis (CF) or other underlying chronic lung disease but can also be isolated from other clinical samples (including blood) and from the environmental samples such as soil, food, sea, and drinking water [1-5]. Its closest phylogenetic relative is the genus Burkholderia and, like members of the genus Burkholderia, the Pandoraea spp. are emerging important respiratory pathogens, particularly in people with cystic fibrosis (CF). Species in this genus are often misidentified as Burkholderia cepacia complex (Bcc) or Ralstonia species owing to overlapping biochemical profiles without differences that reliably distinguish between species [6]. It

(C) The Author(s). 2019 Open Access This article is distributed under the terms of the Creative Commons Attribution 4.0 International License (http://creativecommons.org/licenses/by/4.0/), which permits unrestricted use, distribution, and reproduction in any medium, provided you give appropriate credit to the original author(s) and the source, provide a link to the Creative Commons license, and indicate if changes were made. The Creative Commons Public Domain Dedication waiver (http://creativecommons.org/publicdomain/zero/1.0/) applies to the data made available in this article, unless otherwise stated. 
is because of these limitations that reliable identification requires $16 \mathrm{~S}$ ribosomal DNA sequence analysis.

Cystic fibrosis is caused by mutations in the CFTR (cystic fibrosis transmembrane conductance regulator) gene [7]. The commonest mutation is the deletion of phenylalanine at codon 508 (phe508del). This occurs in about $70 \%$ of patients with cystic fibrosis. The primary function of the CFTR protein is as an ion channel that regulates liquid volume on epithelial surfaces through chloride secretion and inhibition of sodium absorption. The commonly accepted explanation for airway disease in cystic fibrosis is the "low volume" hypothesis. A reduced volume of airway surface liquid causes failure of mucociliary clearance, the lungs' innate defense mechanism [8]. The mucociliary dysfunction means that a patient with CF cannot effectively clear inhaled bacteria. In addition, there is an excessive inflammatory response to pathogens. For a given bacterial load, a person with CF will have up to 10 times more inflammation than a person with a lower respiratory tract infection but without the disease. The reasons for the excessive inflammatory response to pathogens are not fully understood. The abnormal composition and secretion of mucus may also be important. At birth, the airway is uninfected and probably uninflamed [9], but the end result of the abnormalities described above is irreversible airway damage with bronchiectasis and respiratory failure in most patients. Ion and water abnormalities may also cause disease in other epithelia-lined organs.

The main source of morbidity and mortality in CF patients, is the decline in the pulmonary function subsequent to pathogenic colonization with non-fermenting Gram negative bacteria (NFGNB) that they encounter throughout their lives.CF patients are particularly susceptible to infections caused by specific bacterial pathogens such as Pseudomonas aeruginosa, Staphylococcus aureus and Haemophilus influenzae [10].

Although Pandoraea species have also been isolated from sputum samples of CF patients, there is still very little known about their mechanisms of pathogenicity or their roles in CF lung disease [11]. In addition, Pandoraea isolates have been recovered from both CF and nonCF patients from a variety of clinical samples including blood, sputum, urine, the upper airways and lung tissue [12]. The recovery of Pandoraea isolates from the blood of patients indicates that this organism is capable of invading tissue [13, 14]. Antibiotic therapy for treatment of infection is difficult due to the limited number of antibiotics to which these species are susceptible: tetracycline, imipenem and trimethoprim-sulfamethoxazole [15].

However, the clinical significance of colonization with these organisms remains unclear [13] and there are limited and conflicting data available on the clinical outcome of patients colonized with Pandoraea.
Whether Pandoraea spp. is truly pathogenic is not yet fully understood, there is evidence that infection with Pandoraea spp. invokes a host inflammatory response. A number of virulence factors have been associated with clinical virulence of Pandoraea spp. and Bcc, including stimulation of pro-inflammatory cytokine secretion known to cause lung tissue damage (IL-6 and IL-8), biofilm formation and, in the case of Bcc, the ability to invade lung epithelial cells, which may contribute to the persistence of the strains in the CF lung [16-20]. Indeed, biofilm formation by Pandoraea spp. and Bcc has been specifically associated with increased resistance to antibiotics and maintenance of the bacteria in the lung [21-24]. Here, we report the results of isolation and identification of Pandoraea spp. and their ability to form biofilms in vitro, in order to gain insight into their virulence potential in CF lung infections.

In the clinical microbiology laboratory, identification to the species level and differentiation of Pandoraea species from organisms belonging to the Bcc, $R$. pickettii, or $R$. paucula may be problematic $[1,6,25]$. To aid in the identification of these organisms, we used PCR-based identification strategies based on the $16 S$ rRNA gene (rDNA).

\section{Materials and method \\ Sample collection}

From November 2017 to August 2018, following the sedation of CF patients in Namazi hospital (Shiraz, Iran), 31 samples of bronchoalveolar lavage and sputum were collected. Then the samples were transferred to the bacteriology laboratory, faculty of veterinary medicine of Shiraz University, in cold condition. The study was approved by the Ethics Committee of Shiraz University of Medical Sciences.

\section{Culture and isolation}

To obtain strains and to compare culture and PCR results, cultures were performed initially as enrichment cultures. Upon arrival, bronchoalveolar lavage and sputum were cultured in BHI broth and incubated aerobically at $37{ }^{\circ} \mathrm{C}$ for $24 \mathrm{~h}$. Initial enriched cultures were transferred to the enrichment culture plates by serial streaking the cultures on sheep blood agar and incubated aerobically at $37{ }^{\circ} \mathrm{C}$ for $24-48 \mathrm{~h}$.

Then, a loop full of the identified colonies were streaked on a new blood agar and incubated aerobically at $37^{\circ} \mathrm{C}$ for $24 \mathrm{~h}$. Next, from culture positive plates, typical colonies were subjected to gram's staining to study staining reactions and cellular morphology under light microscope. Mixed and gram-negative bacteria were further sub cultured with due care, on both blood agar and MacConkey agar plates for final identification. The growth of typical colonies on both blood agar and MacConkey agar was characterized using blood agar for the presence and type of haemolysis, and the general appearance of colonies 
(morphology, color, shape, size and consistency) and the MacConkey agar for the ability to ferment lactose. Pure cultures of single colony type were further analyzed by catalase and oxidase tests. Confirmation of bacteria to species level was aided by using the biochemical tests including, metabolism of sugars such as glucose, fructose, lactose and tests for metabolic end products such as nitrate reduction, unease and citrate activity, growth on cetrimide agarat $42{ }^{\circ} \mathrm{C}$ and $\mathrm{O} / \mathrm{F}$ medium following standard procedures. For final confirmation, isolates evaluated by two PCR reactions. A first PCR assay was designed to identify all Pandoraea spp. Subsequent PCR assays were designed to identify individual Pandoraea species.

\section{DNA extraction}

A few colonies from the phenotypically characterized pure cultures of Pandoraea from 24 to $48 \mathrm{~h}$ growth on blood agar plates were transferred into $1.5 \mathrm{ml}$ Eppendorf tubes. Total DNA was prepared using the Gram negative DNA extraction kit (Cinagen, Iran). The protocol for Gram negative bacteria as described in the kit was followed for extractions. The extracted DNA were determined to be of good quality and DNA concentration was measured using Nanodrop $(10,000 \mathrm{~V}$ 3.52). DNA concentrations were adjusted to $15 \mathrm{ng} \mu \mathrm{L}^{-1}$ before PCR amplification. Finally, extracted DNA stored at $-20^{\circ} \mathrm{C}$ for further use.

\section{Master mixture of PCR}

The oligonucleotide primers used in this study were synthesized by Cinagen Company (Iran). The forward and the reverse primers sequences are as PanF (5'GGGCTYAACC TGGGAACTGCATTC3'), and PanR (5'CGRYTTGGCRR CCCTCTGTACCG3') [26]. Also PCR evaluations have been done with two universal primers for amplification of $16 S$ rRNA gene. The reaction mixture solution for PCR was prepared using $2 \mu \mathrm{l}$ of $10 \mathrm{x}$ PCR buffer, $1.5 \mu \mathrm{l}(1.5 \mathrm{mM})$ $\mathrm{MgCl}_{2}, 1.2 \mu \mathrm{l}(200 \mathrm{mM})$ dNTPs, $1.2 \mu \mathrm{l}(100 \mathrm{nmol})$ each primer of Pandoraea, $0.2 \mathrm{U}$ of Taq DNA polymerase, $14.7 \mu \mathrm{l}$ $\mathrm{H}_{2} \mathrm{O}$, and $3 \mu \mathrm{l}$ of DNA template to have a final volume of $25 \mu \mathrm{l}$. Using $0.2 \mathrm{ml}$ thin wall microtubes. After initial denaturation (at $94{ }^{\circ} \mathrm{C}$ for $5 \mathrm{~min}$ ), amplification conditions were, denaturation at $94{ }^{\circ} \mathrm{C}$ for $1 \mathrm{~min}$, annealing at $60{ }^{\circ} \mathrm{C}$ for $45 \mathrm{~s}$, and extension at $72{ }^{\circ} \mathrm{C}$ for $1 \mathrm{~min}$. This was repeated for 30 cycles in a Block assembly 96G thermocycler with a hot top assembly (Analytic Jena, Germany), with a final extension of $72{ }^{\circ} \mathrm{C}$ for $10 \mathrm{~min}$ and the PCR products remained in the thermal cycler at $4{ }^{\circ} \mathrm{C}$ until they were collected. All DNA isolation procedures were carried out in a Class II biological safety cabinet in a room geographically separate from that used to set up reaction mixes and also from the 'post PCR' room, in order to prevent crossover contamination by extraneous nucleic acids and in accordance with good molecular diagnostic practice. All reaction mixes were set up in a PCR hood in a room separate from that used to extract DNA, and from the amplification and post-PCR room, in order to minimize contamination. A negative control consisting of all component of reaction mixture except the DNA template was included in all PCR. Positive controls were included in the PCR from colonies that were confirmed according to NCBI gene bank sequencing. In order to evaluate the PCR results electrophoresis in agarose gel was carried out. PCR amplicons were assessed by loading $8 \mu \mathrm{l}$ of the PCR product plus $2 \mu \mathrm{l}$ of loading buffer into separate wells of a $1 \%(\mathrm{w} / \mathrm{v})$ agarose gel (Agarose I; Cinnagen, Iran) containing safe stain. A molecular weight marker (50 bp; Cinnagen, Iran) was loaded into the first well to determine the size of the amplified fragments. The gel was immersed in TBE buffer and subjected to a voltage difference of $100 \mathrm{~V}$ that led to separation of the fragments. Visualization was undertaken using an ultraviolet transilluminator (BTS-20, Japan), and the resulting image was captured by a computer software program (Alpha Ease; Alpha Innotech).

For the final confirmation of isolates of Pandoraea, PCR products of Pan primers for some samples according to the Macrogene Company's instructions were prepared at $50 \mu \mathrm{l}$ volume and were transferred for sequencing. In addition, $16 S$ rRNA gene sequencing for species identification was applied for some of the Pandoraea isolates. The sequences were compared with previously published 16 SrRNA (GenBank accession no.NR152002), Pandoraea gene sequences.

\section{Antimicrobial susceptibility testing}

Antimicrobial susceptibility testing for Pandoraea spp. isolates was performed by disk diffusion method according to the Clinical and Laboratory Standards Institute (CLSI) [27]. Disk diffusion method was performed on Muller-Hinton agar (Merck, Germany), using an inoculum of $10^{5} \mathrm{CFU} / \mathrm{ml}$. Antibiotic disks (Padtan teb, Iran) including amikacin, ciprofloxacin, trimethoprim- sulfumethoxazole, gentamicin, piperacillin tetracycline and imipenem. These antibiotic disks were then placed on agar plates and incubated at 37 ${ }^{\circ} \mathrm{C}$ for $24 \mathrm{~h}$. Escherichia coli (ATCC 25922) and Pseudomonas aeruginosa (ATCC 27853) were used as quality controls strain in each susceptibility determination. The diameter of inhibition zone was measured in millimeters and isolates were scored as susceptible or resistant by comparing results with values recommended on standard charts.

\section{Biofilm assay}

In order to evaluate the ability to create biofilms in Pandoraea spp. isolates used the method of Merritt et al. and Wakimoto model $[28,29]$. Briefly, $100 \mu \mathrm{l}$ of each diluted culture was relocate into individual wells of microtiter dish and grown at $37{ }^{\circ} \mathrm{C}$ overnight. All wells were stained with $125 \mu \mathrm{l}$ of $0.2 \%(\mathrm{w} / \mathrm{v})$ crystal violet solution 
for $10 \mathrm{~min}$ at room temperature. The excess stain was washed twice with distilled water and the plate was allowed to air dried. $200 \mu \mathrm{l}$ of $95 \%$ ethanol was added to solubilize the stained biofilm and incubated for 10-15 min at room temperature. $125 \mu \mathrm{l}$ of each well was transferred into a new microtiter dish. Finally, the optical density (OD) of each sample was measured at $570 \mathrm{~nm}$ by a spectrophotometer. The isolates with the optical density higher than 0.2 were considered as biofilm former isolates.

\section{Results}

Identification of the bacterial species was made by observation of their colonial morphology, gram staining reaction and biochemical characteristics according to Coenyeet al. (2000). Through culture 8isolates of Pandoraea with small gray circle colonies without haemolysis was observed that were rod shapes in gram staining. Catalase and oxidase tests were positive [1].

In this study, Pandoraea strains were isolated from clinical specimens, as in previous studies including bronchoalveolar lavage and sputum of CF patients. Also, most isolates were involved in polymicrobial infections, including Staphylococcus, Pseudomonas, Neisseria flavorans (according to DNA sequencing), Delftia acidovorans (according to DNA sequencing) and Klebsiella.

When these culture positive isolates evaluated by PCR, using the stated primers, all the samples tested for the presence of Pandoraea were identified as $100 \%$ positive (Figs. 1, 2).

\section{Antimicrobial susceptibility}

In this study susceptibility to antibiotics was detected using 7 usual antibiotics prescribed for treatment of chronic lung infection including amikacin, ciprofloxacin, trimethoprim-sulfumethoxazole, gentamicin, piperacillin, tetracyline and imipenem. Antibiotic susceptibility test were indicated all isolates were resistant to gentamicin, amikacin and imipenem and susceptible to ciprofloxacin, trimethoprim-sulfumethoxazole, piperacillin and tetracycline (Fig. 3).

\section{Biofilm assay}

Our target in this study was phenotypical survey of biofilm synthesis ability. According to tests carried out on four Pandoraea isolates evaluated for the ability to create biofilms in LB, TSB and BHI medium, one isolate create strong biofilm in BHI medium, one create strong biofilm in TSB medium, but all four isolate create weak biofilm in LB medium. This results indicate that biofilm formation can differ according the culture media.

\section{Discussion}

Cystic fibrosis (CF) is the most common life-limiting autosomal recessive disease among people of European heritage [30]. In the United States, about 30,000 individuals have CF; most are diagnosed by six months of age. In Canada, about 4000 people have CF [31]. Around 1 in 25 people of European descent, and one in 30 of Caucasian Americans [32], is a carrier of a CF mutation. Although CF is less common in these groups, roughly one in 46 Hispanics, one in 65 Africans, and one in 90 Asians carry at least one abnormal CFTR gene [33, 34]. Ireland has the world's highest prevalence of $\mathrm{CF}$, at one in 1353 [35].

$\mathrm{CF}$ is a common genetic disease. Due to this condition, mucosal secretions in the lung can cause recurrence and persistent respiratory infections. A number of opportunistic pathogens settle in these patients. In most cases, in chronic infections, Pseudomonas, Burkholderia, as well as Pandoraea spp. have been isolated from the lung of CF patients, which play role in emerging pathogenesis. Pandoraea spp. are considered emerging pathogens in the context of CF and are difficult to identify by conventional biochemical methods. Most Pandoraea spp. are present in the lung of CF patients, lung infections, and oral and dental infections. According to the studies conducted to data on patients with CF and lung infection diseases, opportunistic pathogens that have been involved in causing diseases including Pseudomonas, Burkholderia and Pandoraea species, have been isolated and identified [29, 36-38].

One group of bacteria currently considered to be emerging CF pathogens belongs to the genus Pandoraea. The genus Pandoraea was described by Coenye et al. (2000) to differentiate them from other already wellknown CF pathogens, including Pseudomonas and two closely related Gram-negative rods, Burkholderia and Ralstonia species. In fact, phenotypic methods used by many microbiology laboratories commonly lead to the misidentification of Pandoraea species as either Burkholderia or Ralstonia species [2, 4].

Pandoraea infection led to the production of high levels of antibodies, and to a worsened CF lung disease $[4,10,39]$. After first colonization, Pandoraea spp. were able to chronically colonize the CF respiratory tract (CFRT) [10, 40-42], were transmissible between patients $[4,37]$ and can produce severe lung diseases and bacteremia [12, 43]. The pathogenicity appears mainly supported by a pro-inflammatory response induction significantly greater than with $P$. aeruginosa $[19,44]$ and the treatment may be complicated by multidrug resistance conferred by carbapenem hydrolyzing oxacillinases [19]. The potential involvement of Pandoraea in complex interactions between microorganisms within the CF airways was also suggested [44]. 
In current study from 31 samples of bronchoalveolar lavage and sputum, by culture method eight Pandoraea bacteria were isolated and identified. These bacteria were isolated and purified using conventional diagnostic methods such as culture and biochemical tests. But finally by PCR assay just 4 isolates confirmed as Pandoraea. Also, in addition to Pandoraea spp. other bacteria including Staphylococcus, Pseudomonas, Neisseria flavorans, Delftia acidovorans and Klebsiella were also isolated.

In 2001, Coenye et al. identified and investigated species of Pandoraea bacteria. In this study, from 123 samples, Pandoraea (69), Burkholderia (30), Ralstonia (9) and Pseudomonas aeruginosa (5) were isolated and identified. For the first time, PCR testing was performed to identify the member of genus Pandoraea, which were able to detect $P$. apista, $P$. pnomenusa, $P$. sputorum, $P$. pulmonicola and $P$. norimbergensis [26].

Daneshvar and colleagues in 2001 examined the cellular effects of Pandoraea spp. on lung cells in CF patients. The study also found that it was possible to isolate the Pandoraea from the cultures of patient's blood who did not have cystic fibrosis [2].

In the study of Spreet et al., conducted in Canada in 2002, from a total of 447 CF patients in 8 provinces included 5 Pandoraea (1.1\%), 412 Burkholderia (92.6\%) and 5 Ralstonia (1.1\%) bacteria, using culture techniques, biochemical tests and molecular techniques including PFGE, RAPD and RFLP were identified and isolated [45].

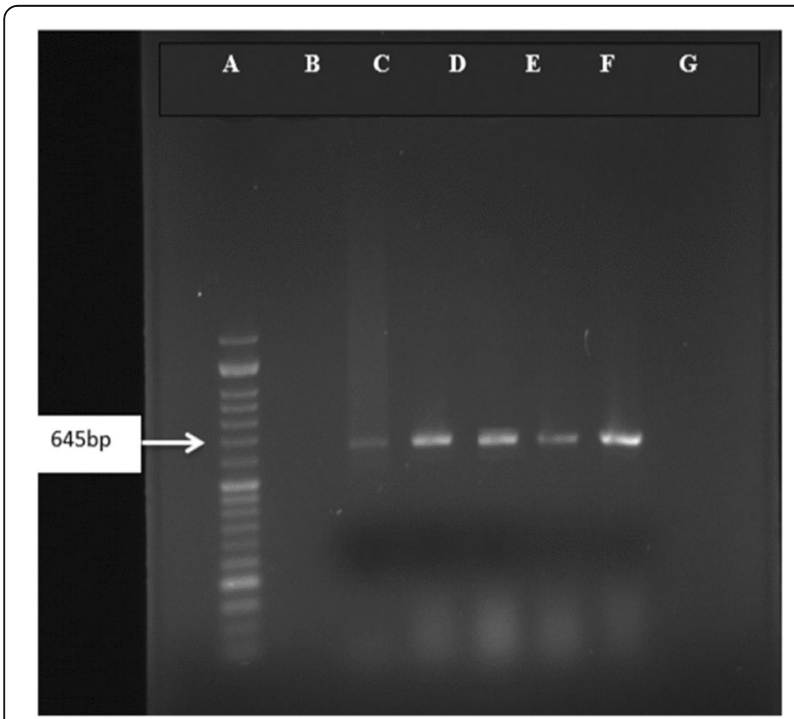

Fig. 1 PCR amplification profile of Pandoraea spp. from DNA isolated directly from samples with PAN primers. Lane a: 50 bp DNA marker, Lane b: Negative control, Lane C: Positive control and Lanes D-G: Positive samples (645 bp amplicon size). It should be noted that 4 samples were absolutely homologues with documented genomic sequencing of Pandoraea in NCBI genomic bank
In 2003, Jorgensen et al, examined the epidemic of $P$. apista in patients with cystic fibrosis. According to the results of this study, it has been shown that P. apista should be added to the ever increasing list of pathogens that can cause chronic lung infections in CF patients [43].

In 2008, Karher et al. examined the pathogenic and genetic characteristics of Pandoraea species in lung epithelial cells. In this study, 17 Pandoraea bacteria were isolated including 5 species: $P$. apista, $P$. pnomenusa, $P$. sputorum, $P$. pulmonicola and $P$. norimbergensis [38].

In a study conducted by Panickar and David (2015) from October 2012 to September 2014 on outpatient, and lavage samples from $182 \mathrm{CF}$ children treated at the Royal Manchester Hospital, 5(3\%) were Burkholderia, 17(19\%) Exophiala, 32(18) Achromobacter and 32 (18\%) Rhodotorula, 18 (10\%) Achromobacter, 1 Ralstonia and 6 (3\%) Pandoraea were identified. This study showed that the number of Pandoraea and Achromobacter bacteria in CF children is increasing [39].

Antibiotic treatment of infections caused by Pandoraea species is difficult because it has been demonstrated resistant against a wide range of antibiotics such as ampicillin, cefazolin, piperacillin, azithroman, broad- spectrum cephalosporins and aminoglycosides, and show a different response to quinolones, trimethoprim-sulfumethoxazole, colistin and carbapenems. Pandoraea species are resistant to most antibiotics, including beta-lactams and aminoglycosides. The bacteria in the subjects evaluated moderate sensitivity to imipenem, doxycycline and ceftriaxone, and an unusual antibiotic susceptibility pattern to carbapenem was also found in Pandoraea bacteria and resistance to meropenem and sensitivity to imipenem has been reported.

The result shows that for antibiotic treatment of Pandoraea infection, antibiogram test for each person has been done individually. Then if a person is allergic to imipenem they can use carbapenem. All Pandoraea species except $P$. apista, G9278 are resistant to amikacin and cefazolin antibiotics, most of which are resistant to broad-spectrum cephalosporins, azithroman and piperacillin. Also, these organisms are resistant to aminoglycosides such as gentamicin, tobramycin and amikacin, but their susceptibility to fluroquinolones is different [40].

Puges et al. (2015), reported that P. sputorum was susceptible to imipenem and resistant to meropenem. This discrepancy has already been described by several authors and is because of meropenem-hydrolyzing $\beta$ lactamases. Some strains are resistant to both imipenem and meropenem, and an imipenem-hydrolyzing oxacillinase named OXA-62 has been identified in $P$. pnomenusa [45]. 


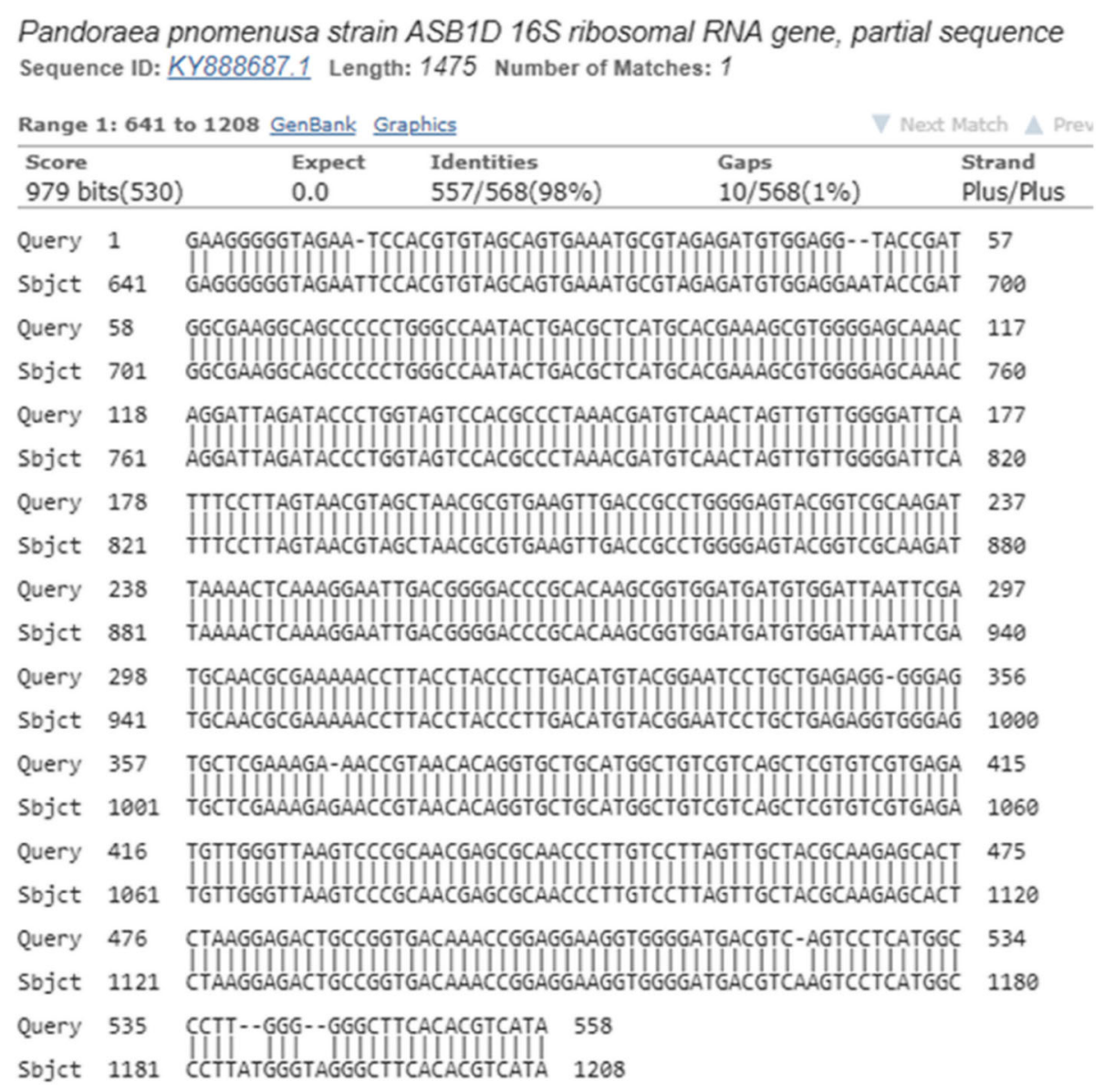

Fig. 2 Genomic sequencing of Pandoraea documented in NCBI genomic bank

In this study susceptibility to antibiotics was detected using 5 antibiotics including amikacin, ciprofloxacin, trimethoprim-sulfumethoxazole, gentamicin and piperacillin. Antibiotic susceptibility test were indicated all isolates were resistant to gentamicin, imipenem and amikacin and susceptible to ciprofloxacin, trimethoprim-sulfumethoxazole, tetracycline and piperacillin.

Biofilms are microbial society encased in extracellular polymeric substances (EPS) [18]. Biofilm formation symbolizes a protective mode of growth that allows microorganisms to survive in hostile environments [46]. Biofilm

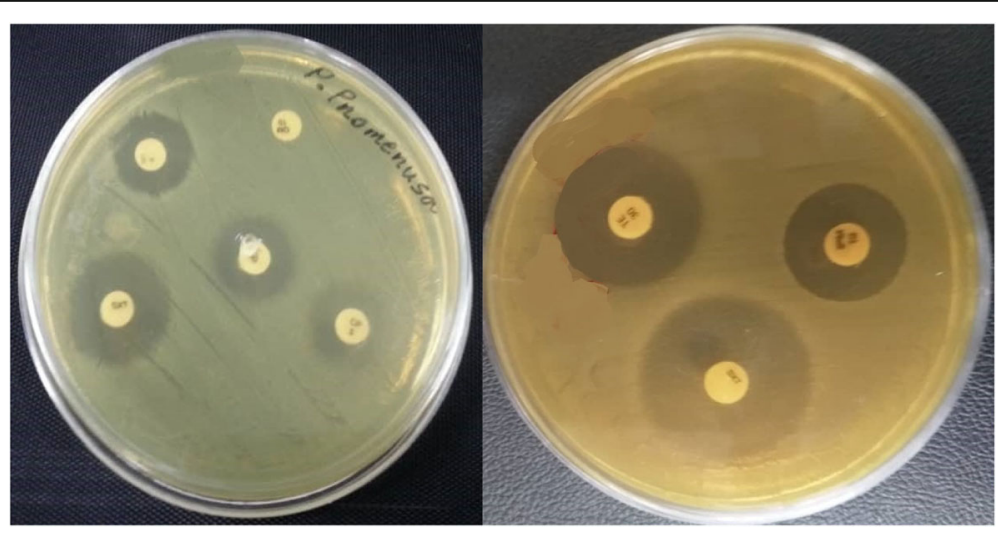

Fig. 3 Antibiogram results of Pandoraea isolates 
is responsible for persistent in chronic infections, due to their inherent resistance to antimicrobial agents. Biofilms are shown as being resistant to killing by a broad range of antimicrobial agents [47]. Some bacteria such as $P$. aeruginosa secrete the exopolysaccharide alginate during infection of the respiratory tract of individuals afflicted with cystic fibrosis and chronic obstructive pulmonary disease [48]. Biofilm production has been considered to be an important determinant of pathogenicity in most infections. In this study all 3 evaluated isolates showed strong biofilm formation ability.

\section{Conclusions}

In conclusionsthe results of our study indicate that Pandoraea species can be isolated from bronchoalveolar lavage and sputum cultures of CF patients. The correct identification of this bacterial species presents a challenge for diagnostic microbiology laboratories. Our study supports the use of genotypic methods to augment routine phenotypic evaluation. The combined use of the two PCR assays described will allow the identification of most Pandoraea species encountered in bronchoalveolar lavage and sputum cultures of CF patients. Most importantly, the use of these assays will substantially reduce the misidentification of Pandoraea spp. as Bcc. These tests will be a valuable adjunct in the evaluation of $\mathrm{CF}$ bronchoalveolar lavage and sputum culture isolates and will allow more precise study of the prevalence and natural history of human infection by this emerging pathogen. Finally our findings should raise awareness about antibiotic resistance in CF patients in Iran and their ability to produce biofilm is an alarm for public health. Thus clinicians should exercise caution in prescribing antibiotics, especially in cases of children infections.

\begin{abstract}
Abbreviations
ATCC: American type culture collection; Bcc: Burkholderia cepacia complex; BHI: Brain heart infusion; bp: base pair; CF: Cystic fibrosis; CFTR: Cystic fibrosis transmembrane conductance regulator; CFU/ml: Colony forming units/ milliliter; CLSI: Clinical and Laboratory Standards Institute;

DNA: Deoxyribonucleic acid; dNTPs: Deoxyribonucleic triphosphates; EPS: extracellular polymeric substances; LB: Luria bertoni; ml: Milliliter; NCBI: National Center for Biotechnology Information; ng $\mu \mathrm{L}-1$ : nanogram/ microliter; nm: nanometer; O/F: Oxiation/ Fermentation; OD: optical density; PCR: Polymerase chain reaction; phe508del: Phenylalanine 508 Deletion; rDNA: ribosomal Deoxyribonucleic Acid; rRNA: ribosomal ribonucleic Acid; Taq: Thermus aquiticus; TBE: Tris Borate EDTA (Ethylenediaminetetraacetic acid); TSB: Triptic soy broth; w/v: Weight/Nolume
\end{abstract}

\section{Acknowledgements}

The authors wish to thank the staff member of department of pathobiology, and all of the people who collaborated with the authors, particularly the laboratories of microbiology and biotechnology (Mr. M. Sorbi and S. Golvagoei), faculty of veterinary medicine, Shiraz University.

\section{Authors' contributions}

This study is the major component of the work toward the M.Sc. thesis of the MD. MT as supervisor of this work provided guidance during the entire experiment. MD wrote the first draft of the manuscript. Then, the whole manuscript critically revised by MT. MAM as an expert in pediatrics pulmonology and bronchoscopy provided bronchoalveolar lavage samples. All authors have read and approved the final version of the manuscript.

Funding

This research was funded by Shiraz University (Grant no. S9530963).

Availability of data and materials

Data sharing not applicable to this article as no datasets were generated or analyzed during the current study.

Ethics approval and consent to participate

Not applicable.

\section{Consent for publication}

Not applicable.

Competing interests

The authors declare that they have no competing interests.

\section{Author details}

${ }^{1}$ Faculty of Veterinary Medicine, Shiraz University, Shiraz, Iran. ${ }^{2}$ Shiraz University of Medical Sciences, Shiraz, Iran.

Received: 20 April 2019 Accepted: 23 July 2019

Published online: 02 September 2019

\section{References}

1. Coenye T, Falsen E, Hoste B, Ohle'n M, Goris J, JRW G, et al. Description of Pandoraea gen. Nov. with Pandoraea apista sp. nov., Pandoraea pulmonicola sp. nov., Pandoraea pnomenusa sp. nov., Pandoraea sputorum sp. nov. and Pandoraea norimbergensis comb. nov. Int J Syst Evol Microbiol. 2000;50:887-99.

2. Daneshvar MI, Hollis DG, Steigerwalt AG, Whitney AM, Spangler L, Douglas MP, et al. Assignment of CDC weak oxidizer group 2 (WO-2) to the genus Pandoraea and characterization of three new Pandoraea genomospecies. $J$ Clin Microbiol. 2001;39:1819-26.

3. See-Too WS, Ambrose M, Malley R, Ee R, Mulcahy E, Manche E, et al. Pandoraea fibrosis sp. nov., a novel Pandoraea species isolated from clinical respiratory samples. Int J Syst Evol Microbiol. 2019;69(3):645-51. https://doi. org/10.1099/ijsem.0.003147

4. Degand N, Lotte R, Le Butor CD, Segonds C, Thouverez M, Ferroni A, et al. Epidemic spread of Pandoraea pulmonicolain a cystic fibrosis center. BMC Infect Dis. 2015;15:583. https://doi.org/10.1186/s12879-015-1327-8,

5. Jeong SE, Lee HJ, Jia B, Jeon CO. Pandoraea terrae sp. nov. isolated from forest soil, and emended description of the genus Pandoraea Coenye et al. 2000. Int J Syst Evol Microbiol. 2016;66(9):3524-30. https://doi.org/10.1099/ ijsem.0.001229.

6. Henry DA, Mahenthiralingam E, Vandamme P, Coenye T, Speert DP. Phenotypic methods for determining genomovar status of the Burkholderia cepacia complex. J Clin Microbiol. 2001;39:1073-8.

7. Riordan JR, Rommens JM, Kerem B, Alon N, Rozmahel R, Grzelczak Z, et al. Identification of the cystic fibrosis gene: cloning and characterization of complementary DNA. Science. 1989:245:1066-73.

8. Matsui H, Grubb BR, Tarran R, Randell SH, Gatzy JT, Davis CW, et al. Evidence for periciliary liquid layer depletion, not abnormal ion composition, in the pathogenesis of cystic fibrosis airways disease. Cell. 1998;95:1005-15.

9. Gibson RL, Burns $\mathrm{JL}$, Ramsey BW. Pathophysiology and management of pulmonary infections in cystic fibrosis. Am J RespirCrit Care Med. 2003;168: 918-51.

10. Martina PF, Martínez M, Frada G, Alvarez F, Leguizamón L, Prieto C, et al. First time identification of Pandoraea sputorum from a patient with cystic fibrosis in Argentina: a case report. BMC Pulmon Medici. 2017;17:33. https:/ doi.org/10.1186/s12890-017-0373-y.

11. LiPuma JJ. Burkholderia and emerging pathogens in cystic fibrosis. Semin Respir Crit Care Med. 2003;24:681-92.

12. Pimentel JD, MacLeod C. Misidentification of Pandoraea sputorum isolated from sputum of a patient with cystic fibrosis and review of Pandoraea species infections in transplant patients. J Clin Microbiol. 2008:46:3165-8.

13. Atkinson RM, Lipuma JJ, Rosenbluth DB, Dunne WM Jr. Chronic colonization with Pandoraea apista in cystic fibrosis patients determined by repetitiveelement-sequence PCR. J Clin Microbiol. 2006;44:833-6. 
14. Stryjewski ME, LiPuma JJ, Messier RH Jr, Reller LB, Alexander BD. Sepsis, multiple organ failure, and death due to Pandoraea pnomenusa infection after lung transplantation. J Clin Microbiol. 2003;41:2255-7.

15. Schneider I, Queenan AM, Bauernfeind A. Novel carbapenem-hydrolyzing oxacillinase OXA-62 from Pandoraea pnomenusa. Antimicrob Agents Chemother. 2006:50:1330-5.

16. Burns JL, Jonas M, Chi EY, Clark DK, Berger A, Griffith A. Invasion of respiratory epithelial cells by Burkholderia (Pseudomonas) cepacia. Infect Immun. 1996;64:4054-9.

17. Cieri MV, Mayer-Hamblett N, Griffith A, Burns JL. Correlation between an in vitro invasion assay and a murine model of Burkholderia cepacia lung infection. Infect Immun. 2002;70:108-6.

18. Duff C, Murphy PG, Callaghan M, McClean S. Differences in invasion and translocation of Burkholderia cepacia complex species in polarized lung epithelial cells in vitro. Microb Pathog. 2006;4:183-92

19. Caraher E, Collins J, Herbert G, Philip G, Murphy PG, Gallagher CG, Crowe $\mathrm{MJ}$, et al. Evaluation of in vitro virulence characteristics of the genus Pandoraea in lung epithelial cells. J Med Microbiol. 2008;57(Pt 1):15-20.

20. Green $\mathrm{H}$, Jones AM. Emerging gram-negative bacteria: pathogenic or innocent bystanders. Curr Opin Pulm Med, 2018; 24:000-000. https://doi. org/10.1097/MCP.0000000000000517.

21. Caraher E, Duff C, Mullen T, Mc Keon S, Murphy P, Callaghan M, McClean S. Invasion and biofilm formation of Burkholderia dolosa is comparable with Burkholderia cenocepacia and Burkholderia multivorans. J Cyst Fibros. 2007;6:49-56.

22. Chernish RN, Aaron SD. Approach to resistant gram negative bacterial pulmonary infections in patients with cystic fibrosis. Curr Opin Pulm Med. 2003:9:509-15.

23. Hoiby N, Krogh Johansen H, Moser C, Song Z, Ciofu O, Kharazmi A. Pseudomonas aeruginosa and the in vitro and in vivo biofilm mode of growth. Microbes Infect. 2001;3:23-35.

24. Yu H, Head NE. Persistent infections and immunity in cystic fibrosis. Front Biosci. 2002;7:d442-57.

25. Moore JE, Coenye T, Vandamme P, Elborn JS. First report of Pandoraed norimbergensis isolated from food-potential clinical significance. Food Microbiol. 2001;18:113-4.

26. Coenye T, Liu L, Vandamme P, LiPuma JJ. Identification of Pandoraea species by 165 ribosomal DNA-based PCR assays. J Clin Microbiol. 2001;39:4452-5.

27. CLSI. M100-S25. Performance standards for antimicrobial susceptibility testing; Twenty-fifth informational supplement; 2015.

28. Merritt J, Kadour D, O'Toole G. Growing and analyzing static biofilms, Curr Protoc Microbiol. 01 2005; Unite1B.1.

29. Wakimoto N, Nishi J, Sheikh J, Nataro J, Sarantuya J, Iwashita M, Manago K, Tokuda K, Yoshinag M, Kawano Y. Quantitative biofilm assay using a microtiter plate to screen for enteroaggregative Escherichia coli. Am J Tro Med Hyg. 2004;71:687e690.

30. Edward T. Essential Medical Genetics, 2011. John Wiley \& Sons. p. 312. ISBN 1-118-29370-3. Archived from the original on 2016-04-17.

31. The canadian facts \& figures on cystic fibrosis. Archived from the original on 2013-06-16.

32. "Genetic Carrier Testing". Cystic Fibrosis Foundation. 2007. Archived from the original on 2010-03-23.

33. Rosenstein BJ, Cutting GR. The diagnosis of cystic fibrosis: a consensus statement. Cystic Fibrosis Foundation consensus panel. J Pediatr. 1998; 132(4):58995. https://doi.org/10.1016/S0022-3476(98)70344-0.PMID9580754.

34. Hamosh A, FitzSimmons SC, Macek M, Knowles MR, Rosenstein BJ, Cutting GR. Comparison of the clinical manifestations of cystic fibrosis in black and white patients. J Pediatr. 1998;132(2):255-9. https://doi.org/10.1016/50022-34 76(98)70441-X.PMID9506637.

35. Farrell P, Joffe S, Foley L, Canny GJ, Mayne P, Rosenberg M. Diagnosis of cystic fibrosis in the Republic of Ireland: epidemiology and costs. Ir Med J 2007;100 (8): 557-560. PMID 17955689. Archived from the original on 2013-12-03.

36. Karatan E, Watnick P. Signals, regulatory networks, and materials that build and break bacterial biofilms. Microbiol Mol Biol Rev. 2009;73:310-47.

37. Panickar J, David T. Prevalence of emerging pathogens in a large paediatric CF centre. J Cyst Fibros. 2015;14:S68.

38. Ambrose M, Malley RC, Warren SJC, Beggs SA, Swallow OFE, McEwan B, et al. Pandoraea pnomenusa isolated from an Australian patient with cystic fibrosis. Front Microbiol. 2016;7:692. https://doi.org/10.3389/fmicb.2016.00692.

39. Mahenthiralingam E. Emerging cystic fibrosis pathogens and the microbiome. Paediatr Respir Rev. 2014;15:13-5. https://doi.org/10.1016/j. prrv.2014.04.006
40. Fernández-Olmos A, Morosini MI, Lamas A, García-Castillo M, García-García L, Cantón R, et al. Clinical and microbiological features of a cystic fibrosis patient chronically colonized with Pandoraea sputorum identified by combining 165 rRNA sequencing and matrix-assisted laser desorption ionization-time of flight mass spectrometry. J Clin Microbiol. 2012;50:1096-8. https://doi.org/10.1128/JCM.05730-11.

41. Kokcha S, Bittar F, Reynaud-Gaubert M, Mely L, Gomez C, Gaubert JY, et al. Pandoraeapulmonicola chronic colonization in a cystic fibrosis patient, France. New Microbes New Infect. 2013;1:27-9. https://doi.org/10.1002/2 052-2975.16.

42. Puges M, Debelleix S, Fayon M, Megraud F, Fayon M, Megraud F, et al. Persistent infection because of Pandoraea sputorum in a young cystic fibrosis patient resistant to antimicrobial treatment. Pediatr Infect Dis J. 2015;34(10):1135-7. https://doi.org/10.1097/INF.0000000000000843.

43. Jørgensen IM, Johansen HK, Frederiksen B, Pressler T, Hansen A, Vandamme P, Koch C. Epidemic spread of Pandoraea apista, a new pathogen causing severe lung disease in cystic fibrosis patients. Pediatr Pulmonol. 2003;36(5):439-46.

44. Costello A, Herbert G, Fabunmi L, Schaffer K, Kavanagh KA, Caraher EM, et al. Virulence of an emerging respiratory pathogen, genus Pandoraea, in vivo and its interactions with lung epithelial cells. J Med Microbiol. 2011;60:28999. https://doi.org/10.1099/jmm.0.022657-0.

45. Speert DP, Henry D, Vandamme P, Corey M, Mahenthiralingam E Epidemiology of Burkholderia cepacia complex in patients with cystic fibrosis, Canada. Emerg Infect Dis. 2002;8(2):181.

46. Caraher E, Collins J, Herbert G, Murphy PG, Gallagher CG, Crowe MJ, McClean S. Evaluation of in vitro virulence characteristics of the genus Pandoraea in lung epithelial cells. J Med Microbiol. 2008;57(1):15-20.

47. Davies D, Parsek M, Pearson J, Iglewski B, Costerton J, Greenberg E. The involvement of cell-to-cell signals in the development of a bacterial biofilm. Science. 1998;280:295-8.

48. Costerton JW, Stewart PS, Greenberg EP. Bacterial biofilms: a common cause of persistent infections. Science. 1999;284:1318e1322.

\section{Publisher's Note}

Springer Nature remains neutral with regard to jurisdictional claims in published maps and institutional affiliations.
Ready to submit your research? Choose BMC and benefit from:

- fast, convenient online submission

- thorough peer review by experienced researchers in your field

- rapid publication on acceptance

- support for research data, including large and complex data types

- gold Open Access which fosters wider collaboration and increased citations

- maximum visibility for your research: over $100 \mathrm{M}$ website views per year

At $\mathrm{BMC}$, research is always in progress.

Learn more biomedcentral.com/submissions 